\title{
Educação Inclusiva: Entre a História, os Preconceitos, a Escola e a Família
}

Inclusive Education: History, Prejudices, and School and Family

Educación Inclusiva: Entre la Historia, los

Prejuicios, la Escuela y la Familia

\section{Sylvia da Silveira Nunes}

Universidade Federal de Alfenas

Ana Lucia Saia \& Rosana Elizete Tavares

Universidade Federal de Itajubá

http://dx.doi.org/10.1590/1982-3703001312014
(cc)BY BY 
Resumo: A inclusão dos alunos com deficiência no ensino regular tem sido cada vez mais discutida. O objetivo do presente ensaio é problematizar as relações entre escola e família, partindo da educação especial, sob a perspectiva da educação inclusiva, isto é, para todos, independentemente de quaisquer particularidades. Para tal, partimos da reflexão sobre alguns aspectos históricos em relação às pessoas com deficiência e seus processos de escolarização. Em um segundo momento, refletimos sobre a complexa dinâmica do preconceito e dos estereótipos no jogo de constituição da subjetividade, para, a seguir, pensar nos pressupostos básicos da educação inclusiva e nos entraves entre família e escola, perpassados pelas políticas públicas educacionais. Concluímos que a diversidade presente na educação inclusiva não é um favor aos grupos historicamente excluídos, mas uma luta pela humanização de todos nós. Luta essa que necessariamente passa pela assunção e superação de preconceitos e estereótipos de todos os envolvidos, uma vez que o convívio com a diferença é um esforço coletivo.

Palavras-chave: Educação Inclusiva. Educação Especial. Preconceito. Família.

\begin{abstract}
Because the trend toward including students with disabilities in regular education has increased, this essay discusses relationships between school and family, starting from special education, within the perspective of inclusive education, that is, for everyone, regardless of any particularities. Therefore, we begin by reflecting on some historical aspects of the schooling process for people with disabilities. Thereafter, we reflect on the complex dynamics of prejudices and stereotypes in the constitution of subjectivity, considering inclusive education's basic assumptions and barriers between family and school within public educational policies. We conclude that the diversity of inclusive education is not a favor to historically excluded groups but a struggle for the humanization of us all. This struggle necessarily involves overcoming the prejudices and stereotypes of all concerned because living with differences is a collective effort.
\end{abstract}

Keywords: School Inclusion. Education, Special. Prejudice. Family.

Resumen: La inclusión de los alumnos con deficiencia en la enseñanza regular ha sido discutida más de forma recurrente. El objetivo del presente ensayo es problematizar las relaciones entre escuela y familia, partiendo de la educación especial, bajo la perspectiva de la educación inclusiva, es decir, para todos, independientemente de cualquier particularidad. Para ello, partimos de la reflexión sobre algunos aspectos históricos con relación a personas con deficiencia y sus procesos de escolaridad. En un segundo momento, reflexionamos sobre la compleja dinámica del prejuicio y de los estereotipos en el juego de la constitución de la subjetividad, para, a seguir, pensar en las suposiciones básicas de la educación inclusiva y en los obstáculos entre familia y escuela, a través de las políticas públicas educativas. Concluimos que la diversidad presente en la educación inclusiva no es un favor para los grupos históricamente excluidos, sino una lucha por la humanización de todos nosotros. Una lucha que necesariamente pasa por la asunción y superación de prejuicios y estereotipos de todos los involucrados, ya que convivir con las diferencias es un esfuerzo colectivo.

Palabras claves: Inclusion Escolar. Educación Especial. Prejuicio. Família.

\section{Relembrando um pouco da história da deficiência e sua escolarização}

Tendo como base a ideia de Hobsbawm (1995) que a história se configura por um amplo processo de continuidade e descontinuidade, iniciamos o presente artigo com alguns pontos históricos sobre a deficiência, para, a partir das reflexões sobre o preconceito, buscar os resquícios, ou a continuidade, de alguns desses fatos históricos.

A cobrança pela perfeição física está presente em praticamente todos os tempos. No curso 
da história, o tratamento dado às pessoas com deficiência sofreu a influência de questões culturais e religiosas. Desde a Bíblia, temos referências a cegos e leprosos como pedintes ou rejeitados pela comunidade. Na literatura antiga, para as pessoas com deficiência intelectual, a única ocupação era a de bobo da corte ou a de palhaço, para diversão dos senhores e de seus hóspedes (Oliveira, 2004).

Segundo Fonseca (2000), na Antiguidade, entre os povos primitivos, o tratamento destinado às pessoas com deficiência assumiu dois aspectos básicos: alguns os exterminavam por considerá-los grave empecilho à sobrevivência do grupo e outros os protegiam e os sustentavam para buscar a simpatia dos deuses ou por gratidão pelos esforços dos que se mutilavam nas guerras.

$\mathrm{Na}$ antiguidade, assim como através dos séculos da era cristã (como na Inquisição e na luta eugenista), as pessoas com deficiência foram objeto de eliminação direta ou indireta, ora em função de sua "inutilidade funcional", ora porque eram consideradas manifestação do demônio ou de castigo divino (Araújo, 2010). Por outro lado, com o passar do tempo, os povos das mais diversas nações passaram a praticar o assistencialismo ou a promover a readaptação da pessoa com deficiência. $\mathrm{O}$ Cristianismo, ainda na Idade Média, interferiu na forma de tratamento dessas pessoas, as quais passaram a ser amparadas em casas de assistência mantidas pelos senhores feudais.

No que diz respeito aos direitos da pessoa com deficiência, a partir da Revolução Industrial, em razão do grande número de acidentes do trabalho, começam a surgir leis que protegem os trabalhadores e garantem a seguridade social através de atividades assistenciais, como atendimento à saúde e a reabilitação aos acidentados.

No início do século XX, estudos médicos e psicológicos contribuíram para o surgimento de novas teorias a respeito da capacidade e inteligência das pessoas, bem como de uma nova visão sobre como tratar as pessoas com deficiência. Helena Antipoff e Ulysses Pernambucano, por exemplo, são dois brasileiros que contribuíram para a educação institucionalizada dos alunos com deficiência, nas primeiras décadas do século XX (Antunes, 2003). As duas grandes guerras mundiais também produziram enorme contingente de mutilados. Além disso, segundo Araújo (2010), na Segunda Guerra Mundial, projetos baseados no ideal de eugenia justificaram o programa denominado de Operação Eutanásia que resultou na morte de mais de 200 mil cidadãos alemães com deficiência.

De acordo com o mesmo autor, as primeiras normas de proteção aos deficientes, defendendo a sua reabilitação, capacitação e inclusão social foram ditadas pela Organização Internacional do Trabalho (OIT), fundada após a Primeira Guerra Mundial, através das Recomendações no 99 de 1955 e no 168 de 1983, e da Convenção no 159 de 1983. O grande número de pessoas mutiladas nas duas guerras mundiais, associado à necessidade de mão de obra para ocupar as vagas de trabalho, ante o grande número de mortes ocorrido, fizeram com que se chamasse a atenção para o tratamento que era reservado para as pessoas com deficiência. Surge, nesse momento, o interesse na reabilitação profissional das mesmas. A interferência da Organização das Nações Unidos (ONU), instituição criada por 51 países após o fim da Segunda Guerra Mundial, impôs políticas sociais para os países-membros, no tratamento diferenciado às pessoas com deficiência.

Em relação à educação, Mendes (2006) lembra que, em virtude da necessidade de reabilitar os mutilados das duas guerras mundiais, apareceu uma resposta mais ampla para a questão da educação das crianças, jovens e adultos com deficiência. Essa educação especial era um sistema paralelo ao sistema educacional geral. No mundo do trabalho, é nesse contexto histórico que nasceu a mencionada Declaração dos Direitos Humanos e o também chamado Paradigma de Serviços, que levou à concessão de algumas vagas de serviços públicos para as pessoas com deficiência (Araújo, 2010).

No decorrer do século XX, a partir da institucionalização da escolaridade obrigatória 
e do reconhecimento de incapacidade da escola de responder pelo aprendizado de todos os alunos, criaram-se, então, as salas especiais dentro de escolas regulares, para onde os alunos considerados com dificuldade de aprendizado eram encaminhados. Sobretudo após as duas guerras mundiais, houve a proliferação das salas e escolas especiais.

Entre 1950 e 1980, teve início o movimento contra a política de segregação, defendendo-se a ideia de integração das pessoas com deficiência, cabendo a elas o máximo esforço para reverter o quadro de deficiência e conseguir sua adaptação ao meio social (Chaveiro \& Barbosa, 2005). Essa é a lógica da integração, que mais tarde será contraposta à concepção de inclusão. $\mathrm{Na}$ integração, a pessoa com deficiência deve se adaptar às instituições sociais, buscando se equiparar aos chamados normais. Já na proposta da inclusão, são as instituições e demais espaços sociais que devem se adaptar e buscar, de fato, atender e se adaptar às pessoas com deficiência.

Um conjunto de fatores contribuiu para a mudança de pensamento na questão da educação das pessoas com deficiência, podendo ser destacados os seguintes: a) intensificação dos movimentos sociais na década de 1960, que alertavam sobre os prejuízos da segregação e da marginalização, alicerçando uma base moral que resultou na proposta de integração escolar, combatendo a segregação; b) as pesquisas científicas sobre a descoberta de formas de ensinar pessoas que, por muito tempo, foram consideradas incapazes de aprendizado. Somaram-se, ainda, a esses fatores, a organização de vários grupos de pessoas com deficiência, pais e profissionais, que passaram a cobrar políticas para fins de garantir direitos e combater discriminações (Mendes, 2006).

A Conferência Mundial de Educação para Todos, em Jointiem, na Tailândia, em 1990 e a Conferência Mundial Sobre Necessidades Educativas Especiais, que aconteceu em Salamanca, na Espanha, em 1994, que resultou na chamada Declaração de Salamanca, são dois momentos históricos marcantes na mudança de paradigma que baliza a educação inclusiva. Na primeira, a educação aparece como preocupação mundial. Na segunda foi aprovada declaração tendo como objetivos: o reconhecimento das diferenças, o atendimento às necessidades de cada um, a promoção da aprendizagem, o reconhecimento da importância da "escola para todos" e a formação de professores. A proposta desses instrumentos é que todos os alunos, inclusive os com deficiência, estivessem matriculados em escolas regulares, defendendo a urgência da reforma educacional para que a educação estivesse ao alcance de todos.

\section{Educação especial e educação inclusiva}

O conceito de educação inclusiva não substitui simplesmente a educação especial. A educação inclusiva parte das lutas e bandeiras da educação especial, mas retoma a educação democrática para todos.

A Declaração de Salamanca ajudou a expandir o conceito de necessidades educativas especiais para todo aquele que precisasse da adaptação da escola para que suas necessidades fossem atendidas e a escolarização, assim, pudesse se encaminhar. Nesse sentido, a educação inclusiva nos lembra que não apenas os alunos com deficiência têm sofrido dificuldades de inserção nos espaços escolares. É a partir desse marco que a educação inclusiva vai se popularizando, partindo sim da educação especial, mas vislumbrando uma nova concepção de educação: a escola precisa incluir não apenas os "especiais", mas todos os alunos.

Assim, a educação especial continua sendo importante para tratar das particularidades da escolarização das pessoas com deficiência. Utilizamos nesse texto, uma concepção de educação especial na perspectiva da educação inclusiva, o que significa dizer que as particularidades que envolvem os alunos com deficiência serão constantemente articuladas com a escolarização dos alunos que não têm deficiência. 
1 Os termos que se referem à pessoa com deficiência foram se alterando ao longo da história. Neste trabalho, serão utilizadas as designações de acordo com os autores, como por exemplo: deficiente, pessoas com necessidades educacionais especiais, pessoa com diferença significativa.
Especificamente sobre a convivência com pessoas com deficiência, vale lembrar a ênfase dada a essa condição, ofuscando outras características, praticamente desconsiderando o sujeito. Para além da deficiência há um sujeito com desejos, vitórias, medos, limitações, com concepções ideológicas, fazeres, gostos, vontades que não devem ser negligenciados em generalizações. Exaltar apenas essa característica desmerece as conquistas, as capacidades, a própria singularidade do sujeito. Amaral (2004) traz argumentos que vão ao encontro dessa perspectiva de que o olhar do outro para a pessoa com deficiência muitas vezes é limitador: "O que conta é o pressuposto básico na cabeça do outro, de que o deficiente ${ }^{1}$ é sua deficiência, vive em função dela: se magoa, se irrita, se fracassa, é porque é complexado; se sobressai é porque precisa compensar" (p. 90). Todas as ações são justificadas em função da deficiência, praticamente se elimina o sujeito para que ela sobressaia. Na educação, o enfoque na deficiência também se faz presente, o que fica claro nas palavras de Skliar (1997):

Se o critério para afirmar a singularidade educativa desses sujeitos é uma caracterização excludente a partir da deficiência que possui, então não se está falando de educação, mas de uma intervenção hermenêutica; se se acredita que a deficiência, por si mesma, é o eixo que define e domina toda a vida pessoal e social dos sujeitos, então não se estará construindo um verdadeiro processo educativo, mas um vulgar processo clínico (p. 06).

Processo clínico é entendido pelo autor como uma prática que busca reduzir ou eliminar a deficiência, comparando-a com um adoecimento. Também é chamada de "intervenção hermenêutica", porque impõe valores e interpretações antes de conceber o aluno como sujeito, de modo a ver a deficiência como fator central do aluno.

Outro aspecto comum na convivência com a pessoa com deficiência é a negação. Mas o incômodo com a diferença reaparece nos discursos que ressaltam o aspecto "normal" valorizado, como cita Amaral (2004) "é o famoso: 'feia, mas tão simpática', 'aleijada, mas tão inteligente, tão sensível, um rosto tão lindo...'" (p. 46). A tendência parece ser a de minimizar, às vezes, a de negar o aspecto errado, diferente ou "anormal". A noção de "ser humano normal", segundo Goffman (2008), pode ter sua origem na abordagem médica da humanidade, ou nas tendências das organizações burocráticas em grande escala, de tratar todos os seus membros como iguais em alguns aspectos. Independentemente da origem, a polarização entre dois agrupamentos, em que se distingue quem tem legitimidade para ser visto como sujeito dos direitos - o normal - e quem ocupa o lugar de, no máximo, alvo da concessão de favores - o anormal, tem sido a maneira como historicamente tem se construído as perguntas a respeito da diversidade humana (Angelucci, 2009).

Se essas concepções tão estereotipadas sobre a pessoa com deficiência ainda estão presentes nos discursos sociais, como fica a inserção dos alunos com deficiência na escola? Muitas vezes, os professores afirmam: "Eu tenho dois casos de inclusão" ou "Eu tenho um especial na minha sala". Vemos claramente que a inclusão aí não tem lugar, uma vez que os alunos em questão são tratados de forma tão diferenciadas que não fazem parte do grupo "alunos" simplesmente. Não se quer, com isso, esquecer as diferenças e, muito menos, tratar todas as diferenças de forma igual. Partimos do pressuposto de que existem diferenças significativas. Ou seja, usar óculos não é o mesmo que ter uma deficiência visual. Porque com os óculos qualquer pessoa tem as mesmas condições que outra pessoa que enxerga bem. Porém, o deficiente visual, seja cego ou portador de baixa visão, tem, com todos os recursos possíveis, pouco acesso às informações visuais e, portanto, sua necessidade especial é ter disponível outras fontes adaptadas de informação para que o conteúdo acessível a ele seja o mesmo daqueles que enxergam.

Assim, o debate do que são as diferenças significativas e de qual espaço social elas têm nos ajudarão a tirar a educação inclusiva do limbo. Por que limbo? É que se adotarmos o conceito de educação democrática não 
precisaremos mais da menção à inclusão, já que será para todos. A educação inclusiva seria então, um lugar de passagem, um paliativo. Algo como as ações afirmativas do tipo cotas universitárias. Elas são necessárias agora. No momento em que tivermos nas salas de aula das universidades tantos negros, índios, população de baixa renda, alunos da zona rural e outros grupos historicamente discriminados, quantos a população local tem, não precisaremos mais das cotas. No entanto, ainda estamos no meio da caminhada. A importância de debater a educação inclusiva é justamente a forma de nos prepararmos e construirmos essa escola para todos. Cada passo dado na reflexão e na experiência com a diferença é um tijolo a mais nessa escola ideal que buscamos.

A contribuição que pretendemos dar a essa discussão é a partir de três temas, bastante problemáticos e complexos: preconceitos, escola e família.

\section{Pensando o preconceito}

É importante diferenciar pré-conceito de preconceito. As ideias pré-concebidas ou pré-conceitos fazem parte da relação do homem com o mundo. Isso significa dizer que o conhecimento não seria possível sem alguma informação anterior sobre o objeto que se pretende conhecer porque é necessário algum ponto de partida para a relação com ele. Assim, a relação sujeito-objeto no momento do conhecimento envolve um caminho duplo: o sujeito parte de algo conhecido para começar a entender o objeto desconhecido e o objeto deixa alguma marca nova no sujeito, permitindo que algo novo seja acrescentado a ele. Essa dinâmica ideal não diz respeito aos preconceitos.

Mas quando, por um lado, o sujeito se fecha para conhecer o objeto, preso unicamente aos seus conhecimentos prévios, ou quando, por outro lado, o sujeito se abre exageradamente ao objeto, sem sobre ele refletir a partir das suas próprias opiniões, temos então a dinâmica do preconceito (Crochík, 2006). Enfim, podemos falar em preconceito quando a relação sujeito-objeto não se refere mais a um processo contínuo de troca mútua.

Outra forma de pensar essa troca contínua entre sujeito e objeto está nos conceitos de projeção e falsa projeção. Horkheimer e Adorno (1986) partem do pressuposto que perceber é projetar. Isto é, para percebermos o mundo a nossa volta, temos de lançar mão de nossos órgãos do sentido em direção aos estímulos sensoriais, projetando sobre o objeto aquilo que pensamos que ele é. Mas a projeção é só o primeiro passo do conhecimento. Na relação com o objeto é possível reconhecer nele o que foi projetado e o que é próprio do objeto, marcando a diferença entre mundo interno e externo. É o que os autores chamam de controle da projeção. Em suas palavras: "[...] o indivíduo precisa de um controle crescente da projeção; ele tem de aprender ao mesmo tempo a aprimorá-la e inibi-la" (Horkheimer \& Adorno, 1986, p. 154).

É essa reflexão que falta ao sujeito preconceituoso, que acaba percebendo o objeto a partir de uma falsa projeção. Tal falsidade está na incapacidade do sujeito de perceber o que é seu e o que é do objeto. Não tendo essa clareza, ele credita tudo ao objeto. É por isso que os autores dizem que, nessas condições, o sujeito... "[...] incha e atrofia ao mesmo tempo" (Horkheimer \& Adorno, 1986, p. 156). É dizer: o sujeito incha porque está cheio de informações do mundo externo, sejam morais, intelectuais, religiosas etc.; porém, ele atrofia e se esvazia ao mesmo tempo porque, sem conseguir refletir sobre o conteúdo dessas informações, nada consegue acrescentar a si mesmo e se torna, tanto mais sem consciência, massa de manobra dos discursos preconceituosos e totalitários. Nesse processo, o sujeito não se dá conta de que aquilo que ele defende como sua opinião nada mais é do que repetição do que já está pronto nos discursos sociais.

A dinâmica do preconceito é complexa e seu estudo mostra que o preconceito depende e independe de sua vítima. Ou seja, o preconceito depende do objeto porque existe algo neste que desperta no preconceituoso o seu 
preconceito. O objeto deve ser de alguma forma um representante da fragilidade, da felicidade sem poder. Segundo Horkheimer e Adorno (1986): "A noção de uma felicidade sem poder é intolerável pois só ela seria a felicidade pura e simples" (p. 143). Porém, o alvo do preconceito informa algo sobre o próprio preconceituoso, ou seja, o preconceito independe do objeto. Neste sentido, pesquisas mostraram que pessoas preconceituosas apresentaram uma tendência a ter preconceito contra diferentes grupos (por exemplo, Adorno, Frenkel-Brunswik, Levinson \& Sanford, 1965; Crochík, 2006). O que significa que há algo no preconceituoso que o faz focalizar seu ódio em grupos, de alguma forma, vistos como frágeis. A vítima escolhida pelo preconceituoso não precisa ser sempre a mesma. Hoje, o ódio é direcionado às pessoas com deficiência. Amanhã, a outro grupo. Não se trata do grupo em questão apenas. Mas da forma como o preconceituoso vive a irracionalidade da ordem vigente, como fica claro nas palavras de Horkheimer e Adorno (1986):

A cólera é descarregada sobre os desamparados que chamam a atenção. E como as vítimas são intercambiáveis segundo a conjuntura: vagabundos, judeus, protestantes, católicos, cada uma delas pode tomar o lugar do assassino, na mesma volúpia cega do homicídio, tão logo se converta na norma e se sinta poderosa enquanto tal (p. 142).

Com isso, queremos enfatizar que aquilo que suscita o preconceito no preconceituoso não é o que o discriminado efetivamente é. Mas o que ele representa, principalmente, no que diz respeito a sua história. Por exemplo, em relação às pessoas com deficiência, o espanto causado pela competência delas mostra claramente a baixa expectativa em relação ao seu desenvolvimento.

A partir de uma relação (ou ausência de uma relação) sujeito-objeto que não permite a abertura ao novo, o preconceituoso deseja eliminar tudo o que não Ihe é familiar. Dessa forma, a angústia do desconhecido despertada pela fragilidade do discriminado é paralisada pelo esforço constante em perceber o objeto de forma estereotipada, ou seja, aprisionada pela repetição. Por exemplo, para um racista, qualquer coisa boa feita por um negro pode ser justificada como arrogância ou vontade de aparecer e qualquer coisa ruim como a certeza de que "se não faz na entrada, faz na saída". Fechando o objeto do seu preconceito em um círculo vicioso constante, o preconceituoso não tem de lidar com conteúdos psíquicos seus. A insegurança constante que vive, devido à forma como as pessoas e coisas do mundo lhe foram apresentadas e da consequente relação que conseguiu estabelecer com o mundo, é disfarçada em uma falsa fortaleza. Embora a fortaleza seja falsa, a frieza com que lida com as pessoas é verdadeira e demonstra sua dificuldade com os sentimentos.

É nesse sentido que Horkheimer e Adorno (1986) afirmam: "O comportamento antisemita é desencadeado em situações em que os indivíduos obcecados e privados de sua subjetividade se veem soltos enquanto sujeitos" (p. 141). Isto é, o vazio em que o preconceituoso vive, porque não pode viver nem o prazer, nem a reflexão, é preenchido pelo ódio a determinados grupos que pela fragilidade exposta, lembram a sua própria fragilidade. Fragilidade essa que o preconceituoso não consegue admitir, nem lidar.

Se o preconceito tem sua origem no fechamento à experiência, esta poderia ser, então, um antídoto contra aquele. Porém, sabemos que não basta colocar juntos dois grupos, sendo um discriminado e outro preconceituoso, para que o preconceito desapareça. Sobre isso, Horkheimer e Adorno (1986) dizem: "[...] ficou provado que as chances do anti-semitismo são tão grandes nas regiões sem judeus como até mesmo em Hollywood" (p. 165). Isso porque existem mais razões no preconceituoso do que no seu alvo para a cristalização da relação que não permite a experiência e a identificação com o outro. A possibilidade de experienciar e de se abrir para o outro envolve relativizar o previamente pensado. Ou seja, aquilo que já era esperado pelo sujeito na sua relação com o outro deve ser de alguma forma transformado pelo que o objeto traz de seu. Entretanto, a possibilidade 
da experiência no capitalismo tardio é cada vez menor. Entendemos capitalismo tardio como define Imbrizi (2005):

É capitalismo porque a dominação entre e sobre os seres humanos tem suas bases na estrutura econômica da sociedade de classes, só que a especificidade de tal opressão é que ela se tornou anônima. Todos os homens sofrem com o controle que, por não saberem de onde vem, transforma-se em destino. E é capitalismo tardio porque 'os homens continuam como apêndice da maquinaria', não só os trabalhadores, pois todo o comportamento do indivíduo em suas mais íntimas emoções submetem-se ao mecanismo social e suas necessidades transformam-se em funções do aparelho de produção (p. 42).

Isso quer dizer que toda a distinção feita até aqui entre pessoas preconceituosas e não preconceituosas tem mais um objetivo didático do que de polarização de dois tipos idealizados. Se podemos entender o preconceito apenas na interface entre indivíduo e cultura, faz-se necessário pensar que a cultura é que permite a formação de pessoas preconceituosas. Para tal, partiremos do conceito de estereótipo, como "ponte" mais facilmente identificável entre o preconceito e a cultura.

Os estereótipos são apresentados pela cultura e têm a clara função de justificativa da dominação. Por um lado, o estereótipo, como a definição precisa de um determinado grupo, por exemplo, funciona como uma forma de orientação da realidade, dado que esta é complexa e ameaçadora. Por outro, ao se apropriar do estereótipo, o sujeito encontra a explicação na cultura para o seu preconceito. Não há, dessa forma, espaço para a dúvida, nem para a reflexão sobre si ou sobre o outro. Como uma resposta rápida e pedindo por uma estabilidade no pensamento, que não admite mudanças, o estereótipo serve para manter as coisas como estão e o sujeito incólume a qualquer alteração na sua forma de pensar.

O pensamento estereotipado utiliza a rigidez de seu conteúdo inalterável. Por exemplo, o estereótipo dos judeus serve para que o sujeito saiba como lidar com eles, como tratá-los, o que pensar sobre eles. A essa distância já definida pelo pensamento estereotipado, nenhuma identificação é possível porque a caracterização do outro como alguém ruim fortalece a ideia do eu como bom. Dessa forma, as condições sociais que permitiram o surgimento do estereótipo são ignoradas e, com o olhar direcionado apenas para o grupo em questão, o sujeito se sente, ilusoriamente, menos inseguro em uma cultura ameaçadora. Mas como essa ilusão é, no fundo, conhecida pelo sujeito, ele sabe que o judeu hoje pode representá-lo amanhã. Isto é, os grupos perseguidos são, como já disseram Horkheimer e Adorno (1986), "intercambiáveis entre si", pois não se trata simplesmente do problema com um grupo $X$, com uma característica peculiar não aceita, mas da própria ordem social que é estabelecida de modo a constituir subjetividades desumanizadas e, por isso, se à vítima de hoje é dado poder suficiente em uma cultura ainda tão desumana, amanhã, muito provavelmente, ela se tornará algoz também. Em relação às pessoas com deficiência, a história mostra oscilações: ora o deficiente deve ser eliminado, ora ele pode funcionar como um oráculo - ambas visões estereotipadas. No entanto, na maioria das vezes, o estereótipo esteve mais voltado para as limitações na vida da pessoa com deficiência e sua exclusão das oportunidades de vida em sociedade.

Dado que o estereótipo e o fechamento à experiência impedem a identificação com o outro, o sujeito preconceituoso tende à repetição. Fazendo sempre o mesmo, fechado às novas experiências, o sujeito não reflete e tende a seguir cada vez mais e de forma automática, o que a cultura diz para ele ser, fazer, desejar. A isso podemos chamar de heteronomia, pois, fechado nas normas sociais e sem a consciência da influência delas na formação de si e do outro, ele não consegue se perceber ao mesmo tempo como sujeito e objeto da realidade que vive. $E$ essa é a tendência que mais se observa na atualidade, pois cada vez mais as pessoas são responsabilizadas unicamente pelo que são, sentem e fazem. Entretanto, cada vez menos há espaço para reflexão e escolha. Se só é possível pensar em um indivíduo autônomo em uma sociedade justa e humana (Horkheimer \& Adorno, 1973), o 
sujeito, fruto da sociedade atual, caminha para longe dessa possibilidade.

Para que o sujeito se transformasse em indivíduo, seria necessário um espaço de reflexão que o permitisse perceber a determinação social, bem como "[...] conscientizar-se de que sua autopreservação depende da preservação da natureza e da coletividade" (Imbrizi, 2005, p. 80). Ou seja, a natureza social do homem que the permite se individuar por meio da cultura significa estabelecer com ela uma relação de proximidade e distância, de modo que seja possível a reflexão sobre o que a cultura é sem, contudo, negá-la e sem estar de acordo com ela em tudo. No entanto, como o indivíduo só pode se constituir pela cultura, é ela que possibilita ou não a sua individuação. E quanto menos ela o permite, mais os preconceitos se apresentam como defesa do sujeito.

A partir dessa breve exposição, percebemos que a lógica do preconceito não é simplesmente racional. O que equivale a dizer que somente as ações informativas não são suficientes para combatê-lo. Com a divulgação cada vez mais forte dos valores democráticos, em que se diz que todas as pessoas são iguais e se valoriza o respeito à diferença, o preconceituoso sabe que qualquer sentimento discriminatório contra qualquer grupo é mal visto socialmente. Ao admitirmos a irracionalidade do preconceito, podemos nos perguntar sobre a possibilidade de estudá-lo por meio racionais. Pressupomos, entretanto, que:

[...] se o preconceito é algo irracional, a forma de expressá-lo nem sempre o é, e, assim, devemos nos ater, inicialmente, tanto às explicações psicanalíticas sobre as modificações a que todos os indivíduos devem se submeter para poder pensar, quanto ao invólucro pretensamente racional que os preconceituosos dão às suas teses" (Crochík, 2006, p. 30).

É esse invólucro racional que pretendemos abordar nos impasses entre a escola e a família no que se refere à educação inclusiva.

\section{Escola e família: alguns impasses e reflexões}

Angelucci (2002) nos lembra de que a educação inclusiva lança luz sobre os problemas da escola já existentes antes das políticas de inserção de alunos com deficiência no ensino regular. Como já dissemos, nossa concepção de educação inclusiva parte das questões levantadas pela deficiência, mas não se limita a elas, porque é a própria escola que precisa ser repensada como escola para todos.

As políticas públicas educacionais referentes à educação inclusiva não diferiram quanto a outras políticas públicas para a escola, pois os atores sociais mais importantes no processo estiveram fora das decisões: professores, alunos e suas famílias. Assim, é compreensível que professores tenham sentido seus saberes desconsiderados e isso é uma violência simbólica a sua experiência e dedicação à escola. No entanto, também não nos cabe estacionar na ideia: "A escola não está preparada para a educação inclusiva". A pesquisa de Celio Sobrinho e Alves (2013) mostra que alguns dos professores que afirmaram esse despreparo não quiseram participar das iniciativas de debate na escola sobre o tema. Tal fato pode nos ajudar a pensar, apesar da desconsideração do Estado pelo saber docente ao impor de "cima para baixo" a obrigatoriedade da educação inclusiva, será que muitos de nós não estaríamos nos escondendo atrás desse despreparo para não enfrentar os desafios da educação inclusiva? Desafios esses que já estão presentes na escola regular, pois ouvimos também dos professores: como lidar com o aluno mentiroso? E com o aluno manipulador? O que sofreu uma perda na família? E com o aluno tímido? Nenhum curso de formação de professores consegue oferecer uma "receita" de preparo a todo e qualquer tipo de aluno. As possibilidades de formação da educação estão nas relações estabelecidas dentro da escola, partindo de sua estrutura educacional e das pessoas que compõem esse dia a dia.

Além disso, a ideia de estar "preparado" carrega um equívoco: de que é possível nos "preparar" para o encontro com o outro. As relações humanas são o encontro 
com o inesperado, a novidade que está no outro, lembremos da dinâmica explicada acima sobre o preconceito: no encontro com o outro há algo que aprendo que é novo, se isso não acontece, é porque estou preso ao meu preconceito. E a educação, na perspectiva que estamos adotando, como experiência formativa e direito ao saber, precisa justamente desse encontro, sem regras pedagógicas controladoras.

Nesse sentido, compartilhamos com Voltolini (2009) a perspectiva de que o encontro com o outro é necessário para a educação ocorrer:

O encontro comporta o imprevisível, mas também o criativo, a solução em cima da hora, aquela que leva em consideração uma série de elementos e não apenas a pergunta organizada de um aluno transmitida a posteriori pelo recurso tecnológico.

O encontro é o maior indicativo da presença, já que alguém se move, ri da minha piada, faz uma expressão com o rosto que inclina meu modo de pensar em outra direção, enfim, sinais de uma riqueza que o contato contém e que me permitem desviar da rota pelo encontro (Voltolini, 2009, p. 135, destaques do autor).

Na citação acima, o autor aborda os problemas concernentes ao ensino a distância, que ele afirma não se tratar de educação, por não permitir esse encontro. Para nossa discussão, vale lembrar que o valor das informações sobre os diferentes tipos de deficiência e as formas de acessibilidade que garantem ao máximo o direito aos mesmos conhecimentos, bem como as reflexões sobre as minorias (não de número, mas de poder), suas histórias, dados sobre sua pouca representatividade etc. é inegável e tem caráter formativo, mas não necessariamente "preparatórios".

Para entender essa inviabilidade do "preparar" precisamos nos lembrar de que as pessoas pertencentes a determinado grupo estigmatizado, como nos diz Goffman (2008), não são todas iguais. Isso significa que, por mais que eu estude a surdez e a Língua Brasileira de Sinais (Libras), por exemplo, isso não me garante a fórmula perfeita para me relacionar com todo e qualquer surdo. É que os surdos não são todos iguais. Eles se diferenciam como todos nós: classe social, gênero, idade, opção político-partidário, profissão, religião, gosto pela arte etc. Além disso, existem diferenças da própria deficiência: momento da perda auditiva, grau da perda, reação da família, apoio institucional das áreas de educação, saúde, assistência social etc. Isso nos leva a desconfiar de frases como: "Todo surdo é irritado", "Toda pessoa com síndrome de Down é afetuosa", "Todo cego tem dons artísticos" etc. Nesse "todo" que busca homogenizar o que é impossível de ser generalizável, vemos uma "violência". É a violência do estereótipo.

Também a família sofre com o estereótipo. A família é um grupo social atravessado por todas as questões sociais a que todos estamos sujeitos. Ou seja, se vivemos ainda em um mundo com diferentes tipos de preconceitos aos grupos estigmatizados, então, a família não está imune aos preconceitos, estigmas e estereótipos. No entanto, as famílias têm diferentes reações às diferenças. Foquemos no caso da deficiência. Há familiares que estimulam seu ente com alguma limitação física de forma bastante próxima ao que se cobra dos outros membros da família. Quando isso acontece, costumamos ver pessoas mais inseridas socialmente do que nas famílias em que há insegurança ou superproteção que influencia a criança ou adulto com deficiência.

É nesse sentido que o "estar preparado" pode ser perigoso pois dependendo do preparo, o olhar para o diferente será mais "recheado" de preconceitos e estereótipos do que um olhar ingênuo ou "despreparado", que aposta na capacidade do outro, sem focar exclusivamente nas suas limitações. Além disso, seguindo a mesma lógica que Angelucci (2002) apresenta sobre a atenção que a educação inclusiva chama para os problemas já existentes na educação, podemos pensar as antigas e conflituosas relações entre família e escola.

Patto (1992), há mais de 20 anos, já mostrou os desencontros entre as famílias pobres e os professores de escola pública. Falas preconceituosas de professoras sobre o descaso 
da família são contrapostas com as falas de dedicação dos pais. Mas trata-se de uma dedicação não visível ao observador mais desatento. Porque para essas pessoas, a escola nem sempre é um espaço familiar. Muitos pais não tiveram boas experiências na escola, evadiram muito cedo, tiveram que trabalhar e parar de estudar. São frutos de um sistema escolar seletivo. Mas não é isso que desejam para os filhos. Expressam sua angústia pelas dificuldades do filho e todos são unânimes em valorizar a escola.

Além de denunciar uma ilusão dos profissionais de educação de que é possível conhecer o cotidiano de uma família por pequenos "sinais" que se observa na aula, nas reuniões, na entrada e saída da escola, a atualidade do texto pode ser vista na citação de uma professora: "Se é bem alimentada, se tem carinho de pai e mãe e atenção do pai, alguém que olhe o caderninho dela, não tem por onde ser reprovada" (p. 113). Essa professora mostra com essa frase uma concepção de que o sistema educacional está imune a críticas, mas a família, não. Esta deve fazer aquilo que a escola não consegue fazer.

Enfim, podemos perceber um fogo cruzado entre escola e família. Fogo cruzado sem vencedores. É importante assumirmos que, muitas vezes, profissionais da educação e família são representantes de classes sociais diferentes e suas falas e atitudes denunciam, ainda, um abismo de comunicação, em que cada parte espera que a outra faça aquilo que não conseguiu realizar.

Moysés (2001) também mostra essas discrepâncias em seu interessante livro "A institucionalização invisível: crianças que-não-aprendem-na-escola". Partindo de uma visão crítica de avaliações padronizadas tipo teste psicológico, já presente em artigo anterior (Moysés \& Collares, 1997), a autora, que é médica, avalia crianças apontadas pelos professores como futuros repetentes logo no início do ano. E seu método de avaliação visa superar a artificialidade dos testes e, em uma via contrária, parte do que a criança gosta de fazer para avaliar o seu desenvolvimento e conhecimentos de leitura e escrita. A título de exemplo, ouçamos o caso de Daniela, que no momento da pesquisa tinha 8 anos e 4 meses. Para todas as crianças avaliadas, a autora faz um resumo sobre a fala da professora, da mãe ou pai, da própria criança e, para finalizar, sua fala de médica:

\section{A professora}

É muito magrinha, muito enjoada, nunca come a merenda. Acho que é subnutrida. Ah! É sim, o caso dela é gritante... De desnutrição, de relaxo da mãe. É assim mesmo, a gente vê muito, não sabe a alimentação que a criança precisa comer, dá porcaria, aí fica desnutrido. O médico já explicou isso várias vezes, ele vinha aqui examinava e dizia: "desnutrição, a criança quer aprender, mas não aprende". Mas não adianta, as mães não se interessam, não levam no postinho, a mãe acho que nunca levou no médico.

\section{A mãe}

Ela nasceu bem, de nove meses, no hospital. Pesou três duzentos e cinquenta. Teve alta no segundo dia. Nunca teve nenhum problema. Sempre acompanhei no Centro de Saúde. O médico sempre dizia que ela estava crescendo bem, gordinha sempre.

Entrou na escola com seis anos e meio, queria muito ir, mas não aprendeu a ler, foi reprovada. Não sei por quê, a professora nunca falou nada, nunca me chamou pra nada.

\section{Daniela}

Eu? Quando crescer quero trabalhar. De vender doce, é um bom trabalho, todo mundo compra.

Eu repeti porque não aprendi. \{Por que você não aprendeu?\} Por que? Não sei...

\section{A médica}

A mãe tem o cartão com a evolução de peso e altura nos dois primeiros anos de vida: normal. Nunca teve qualquer doença nutricional. Teve um acompanhamento modelo na saúde, 
trazendo para a consulta de hoje todos os cartões, de agendamento, de vacinação e de medidas.

Criança normal. Desenvolvimento normal. Estado nutricional normal (Moysés, 2001, p. 173/174).

Essa longa citação mostra que a fala da professora e da família parece não dizer da mesma criança. Ainda vivemos isso dentro da escola: a impressão é de que trata-se de mundos paralelos. É preciso construir pontes para superar esses abismos de comunicação. A educação inclusiva não fica imune a essa lógica que compõe a estrutura da escola há décadas. No entanto, há possibilidades de pontes entre esses dois mundos: escola e família. Celio Sobrinho e Alves (2013), por exemplo, relatam uma pesquisa-ação realizada em uma escola pública de Vitória, no Espírito Santo. Buscando superar esse hiato de comunicação entre família e escola, foi organizado por pais e profissionais da referida escola encontros sistemáticos mensais de pais de alunos com deficiência e professores. Os encontros foram marcados também pela organização de fóruns para a comunidade fora da escola: outros professores de outras escolas etc.

A pesquisa mostrou que os encontros mobilizaram a assimetria notada entre familiares e especialistas. Com espaço de diálogo e formação, pais e professores, puderam assumir conflitos, construir novas possibilidades e com isso, colocaram "[...] em movimento a balança do poder da relação família e escola" (Celio Sobrinho \& Alves, 2013, p. 337 , destaques dos autores).

\section{À guisa de conclusão}

Professores e demais profissionais da educação são destituídos de poder ao se verem reféns das políticas educacionais impostas de forma tão pouco democrática. Por outro lado, esse poder subtraído não desfaz as antigas relações desiguais entre escola pública e familiares dos alunos, talvez, justamente potencialize tais relações de poder. Entretanto, a ponte que pudermos criar entre família e escola serão benéficas para todos: alunos, pais, professores, comunidade etc. Para tal, não fechamos com receitas prontas, mas justamente com a reflexão sobre a abertura para o outro diferente: o que ele está trazendo de diferente que pode me levar a novas reflexões e aprendizado? O que os pais têm para contar sobre a experiência de escolarização dos seus filhos? Será que o aparente desinteresse dos pais não esconde a vergonha de estarem presente em um lugar que lhe foi traumático e com pessoas que são consideradas "superiores"? E os familiares excessivamente inseguros: será que não estão atualizando as dificuldades que eles mesmos já viveram na escola? Só poderemos responder essas perguntas no diálogo. Lembrando que dialogar não significa falar a mesma língua e concordar sempre. Ao contrário. Talvez tenhamos que descobrir na fala do outro o espelho do mal do nosso próprio preconceito. $\mathrm{E}$, assim, com mais conhecimento sobre nós mesmos, buscar alternativas para superar nosso pensamento, fala e ação, muitas vezes, preconceituosos.

A diversidade presente na educação inclusiva não é um favor aos grupos historicamente excluídos, mas uma luta pela humanização de todos nós. Quando não conseguimos lidar com as diferenças que nos rodeiam perdemos uma oportunidade de caminhar na nossa própria evolução. Assim, quando privamos os alunos de conviverem com outras crianças com dificuldades visuais, motoras, auditivas, intelectuais ou com outras diferenças marcantes tais como classe social, lugar de origem, religião, opção sexual etc., falhamos na sua formação, porque, quando adultas, talvez terão menor facilidade de lidar com essas mesmas pessoas.

Enfim, assim como pensamos que uma rampa é uma melhor forma de locomoção tanto para pessoas com mobilidade reduzida quanto para quem tem uma mobilidade comum, o mesmo raciocínio se entende no convívio com a diferença permitido na escola: conhecendo diferentes modos de ser, facilitamos a nossa própria vida, pois flexibilizamos nosso olhar para o mundo e podemos superar a lógica do preconceito que tanto conhecemos. Porém, esse convívio com a diferença é um esforço coletivo: família, escola, poder público, comunidade, todos precisam dar sua contribuição. 
Referências
Adorno, T. W., Frenkel-Brunswik, E., Levinson, D. J., \& Sanford, R. N. (1965). La personalidad autoritaria. Buenos Aires: Editorial Proyección.

Amaral, L. A. (2004). Resgatando o passado: deficiência como figura e vida como fundo. São Paulo: Casa do Psicólogo.

Angelucci, C. B. (2009). O educador e o forasteiro: depoimentos sobre encontros com pessoas significamente diferentes. Tese de Doutorado, Instituto de Psicologia, Universidade de São Paulo, São Paulo, SP.

Angelucci, C. B. (2002). Uma inclusão nada especial: apropriações da política de inclusão de pessoas com necessidades especiais na rede pública de educação fundamental do Estado de São Paulo. Dissertação de Mestrado, Instituto de Psicologia, Universidade de São Paulo, São Paulo, SP.

Antunes, M. A. M. (2003). A psicologia no Brasil: leitura histórica sobre sua constituição. São Paulo: EDUC.

Araújo, J. N. G. (2010). A inclusão das pessoas com deficiência no mercado formal de trabalho. In: A. M. Mendes, R. C. Merlo, C. F. Morrone, \& E. P. Facas (Orgs.). Psicodinâmica e clínica do trabalho: temas, interfaces e casos brasileiros. Curitiba, PR: Juruá.

Celio Sobrinho, R., \& Alves, E. P. (2013). A relação família e escola em um contexto de escolarização do aluno com deficiência: reflexões desde uma abordagem sociológica funcional. Educar em Revista, 49, 323-338.

Chaveiro, N., \& Barbosa, M. A. (2005). Assistência ao surdo na área de saúde como fator de inclusão social. Revista da Escola de Enfermagem da USP, 39(4), 417-422.

Crochík, J. L. (2006). Preconceito: indivíduo e cultura (3a ed.). São Paulo, SP: Casa do Psicólogo.

Fonseca, R. T. M. (2000). Proteção jurídica dos portadores de deficiência. Revista de Direitos Difusos, 4(1), 481-486.
Goffman, E.(2008). Estigma: notas sobre a manipulação da identidade deteriorada. Rio de Janeiro, RJ: LTC.

Hobsbawm, E. (1995). A era dos extremos: o breve século XX: 1914-1991 (M. Santarrita, trad). São Paulo, SP: Companhia das Letras.

Horkheimer, M., \& Adorno, T. W. (1986). Dialética do esclarecimento. Rio de Janeiro, RJ: Jorge Zahar.

Horkheimer, M., \& Adorno, T. W. (1973). Temas básicos de sociologia. São Paulo, SP: Cultrix.

Imbrizi, J. M.(2005). A formação do indivíduo no capitalismo tardio: uma análise de estudos que vinculam a esfera subjetiva ao mundo do trabalho. São Paulo, SP: Hucitec.

Mendes, E. G. (2006). A radicalização do debate sobre inclusão escolar no Brasil, Revista Brasileira de Educação, 11(33), 387-405.

Moysés, M. A. A. (2001). A institucionalização invisivel: crianças que não aprendem na escola. Campinas, SP: Mercado de Letras.

Moysés, M. A. A., \& Collares, C. A. L (1997). Inteligência abstraída, crianças silenciadas: as avaliações de inteligência. Psicologia USP, 8(1), 63-89.

Oliveira, A. M. (2004). Um duplo aspecto da noção de obstáculo epistemológico na educação matemática. In: C. P. A. Alves, \& O. Sass (Orgs.), Formação de professores e campos do conhecimento (pp. 63-67). São Paulo, SP: Casa do Psicólogo.

Patto, M. H. S. (1992). Família pobre e escola pública: anotações de um desencontro. Psicologia USP, 3(1), 107-121.

Skliar,C.(1997). Educaçãoeexclusão:abordagem sócio-antropológicas em educação especial. Porto Alegre, RS: Mediação.

Voltolini, R. (2009). Educação a Distância: algumas questões. Educação: Temática Digital. 10(2), 123-129. 


\section{Sylvia da Silveira Nunes}

Universidade Federal de Alfenas, Alfenas - MG. Brasil.

E-mail: sylviasnunes@yahoo.com.br

\section{Ana Lucia Saia}

Mestre pela pela Universidade Federal de Itajubá, Itajubá - MG.

Email: anasaia@projesom.com.br

\section{Rosana Elizete Tavares}

Mestranda pela Universidade Federal de Itajubá, Itajubá - MG. Brasil.

E-mail: rosanatavares@unifei.edu.br

\section{Endereço para envio de correspondência:}

Universidade Federal de Alfenas, Conselho de Ensino, Pesquisa e Extensão, Instituto de Ciências Humanas e Letras. Rua Gabriel Monteiro da Silva, 700. Centro. CEP: 37130-000. Alfenas - MG. Brasil.

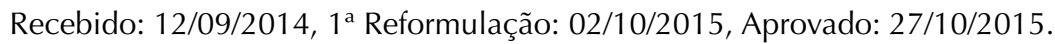

